\title{
A NOTE TO READERS
}

Coronavirus-A Turning Point for Humanity?

sthis book goes to press, the coronavirus pandemic dominates
people's minds and lives. In the midst of widespread death,
suffering, and lockdowns, there is pervasive fear, anxiety, and blame. From Washington to Beijing and London to Delhi, policy circles and the media focus on reopening economies that have ground to a halt. And notable experts including Henry Kissinger, Yuval Noah Harari, and Kishore Mahbubani speculate on global economics, geopolitics, the future of liberal democracy, and more in the "world after coronavirus."

Sadly, human economics and politics remain the center of the universe in these conventional policy, media, and expert analyses. It's as if nature did not exist and as if the health of the human economy were independent of planetary health. If we could broaden our horizons just a bit, might we transform present anguish into tremendous opportunity that can avert far greater suffering in the future? Might this present crisis forced on us be seen as a turning point in human history and the state of the world? Might we even be brave enough to think beyond returning to business as usual and find a new way forward to greater planetary and human health, harmony, sanity, and prosperity?

We never would have voluntarily chosen such shock treatment to effect needed change. But we can still be honest enough to acknowledge that stopping our runaway fossil fuel-based growth economy in its 
tracks cut greenhouse gas emissions faster and more deeply than all the years of climate negotiations put together. It brought clean air and blue skies to the world's most polluted cities. It stopped the flow of toxic effluents and industrial pollution into the world's waterways, which at least briefly sparkled with clear water like never before. And it brought animals and aquatic life back to previously uninhabitable habitats-saving many species, at least temporarily, from the brink of extinction. Sadly, those gains may be short-lived.

But will we now turn our backs on these realities that can save lives and economic costs far exceeding the coronavirus toll? In recent years air pollution from fossil fuels has killed 4.5 million people a year, costing the global economy an estimated $\$ 2.9$ trillion (3.3 percent of global GDP) in health care costs and lost economic productivity annually. ${ }^{2}$ And Lord Nicholas Stern, former World Bank chief economist, has estimated that continuing to emit greenhouse gases at pre-pandemic rates will cost the global economy between 5 percent and 20 percent of world GDP annually in economic damages due to increased droughts, floods, fires, sea level rise, and other climate change impacts on food production, water resources, health, and more. Stern calls climate change the "greatest and widest-ranging market failure ever seen."

Will we look back on the 2020 coronavirus woes as child's play next to the suffering that awaits us, or as the moment humanity seized a golden opportunity to leave destructive habits behind, to avoid catastrophe, and to create a better future?

Forcibly shutting down power plants, industry, and transportation and thereby drastically cutting coal and oil consumption, as COVID-19 has done, has already produced demonstrable savings in pollution costs. As of April 2020, preliminary estimates showed 11,000 avoided air-pollution-related deaths in Europe, and two months of pollution reduction in China likely saved the lives of 4,000 children under age 5 and 73,00o adults over 70. ${ }^{4}$ Later in this book we'll look at how levels of pollution, greenhouse gas emissions, and other social and environmental realities are translated into lives lost or saved, and increases or decreases in illness incidence, health care costs, productivity, agricultural production, and other economic costs and benefits. For now it's enough to note 
that these avoided pollution-related deaths and costs are the direct result of the pandemic that the world experienced in 2020.

Thus Harvard University researchers also have found that cleaner air would have sharply reduced the coronavirus death toll and costs. They found that areas with higher pollution in the United States had significantly higher COVID-19 death rates, because PM2.5 particles increase breathing troubles, hypertension, heart disease, and diabetes; weaken the immune system; and fuel inflammation in the lungs and respiratory tract. That in turn increases risks of getting COVID-19 and of severe symptoms and complications. According to Francesca Dominici, Harvard biostatistics professor, "If you're getting COVID, and you have been breathing polluted air, it's really putting gasoline on a fire." 5

On April 30, 2020, the International Energy Agency (IEA) forecast that the decline in oil and coal use due to coronavirus lockdowns would cut $\mathrm{CO}_{2}$ emissions by nearly 8 percent in 2020-the largest annual decrease ever recorded, nearly six times the 2009 record drop due to the global financial crisis, and twice as steep as all emissions declines since World War II combined. IEA Executive Director Dr. Fatih Birol noted that a rebound in emissions is not inevitable if there is investment in renewables and other green recovery measures that "can create jobs, make economies more competitive and steer the world towards a more resilient and cleaner energy future."'

We all want a quick end to this horrid coronavirus and the torment, grief, and insecurity it has brought. At the same time, we know we've given nature a break. We've suddenly been forced to shop, drive, travel, produce and consume a lot less. So weve depleted fewer resources, cleaned the air and water, and staved off climate change damages at least a bit longer. Our usually frenetic lifestyles have slowed, and we've tempered our usually insatiable appetites. We've also seen the perils of structural inequities that have rendered the poor, racial minorities, and others so much more vulnerable to this pandemic and deprived too many of life-saving interventions. And we've learned the hard way the necessity for global cooperation against a common threat. Perhaps most important and positively, we've proven we're capable of major forthright 
action in the face of crisis-from national lockdowns to putting off the Olympics to sharply reducing our air travel.

When this virus goes, as it most certainly will, do we need to crank up business as usual and to go back into economic overdrive with potentially catastrophic future results? Or can we take this moment to forge a new path toward a more sustainable and equitable future, in which we live in greater harmony with nature and share its abundant resources equitably and efficiently? If we do not do so, then this present COVID-19 crisis will pale by comparison with the suffering caused by future climate change calamities to which the horrendous Australian fires of 2019-20 and the U.S. west coast fires of August-September 2020 are just a small precursor of what will come. At the time of writing, the greatest promise seems to come not from national leaders but from city mayors-from Paris to Bogota to Milan-who are promising a low-carbon, sustainable recovery from the pandemic with new networks of bicycle lanes and pedestrian walkways, commitments to renewable energy, and more. ${ }^{7}$ On 28 September 2020, 64 countries launched a Leaders' Pledge to put the climate and nature at the heart of post-pandemic recovery plans. But without the support of the USA, China, Brazil, Russia, India, Australia and others who refused to sign, it is unclear whether and how the pledge will translate into effective action.

To date, we've not been wise or courageous enough to change direction willingly. Now, through no choice of our own, we've been delivered a remarkable-perhaps once-in-a-lifetime-opportunity in the midst of immense distress. The entire purpose of this book is to help chart a new, different, and practical way forward to a much brighter future. The moment could not be more timely. The practical means and tools are in our hands, starting with an honest accounting of the true benefits and costs of economic activity. We know what to do and how to do it. With just a little will, bravery, and wisdom, we can do it! May this book make a small contribution to the well-being of this planet and all its inhabitants. And may our present woes quickly transform into security and happiness for our children and their children. 
WHAT REALLY COUNTS 
